Article

\title{
Host Associations of Culex (Melanoconion) atratus (Diptera: Culicidae) and Culex (Melanoconion) pilosus from Florida, USA
}

\author{
Lawrence E. Reeves*(D), Isaiah Hoyer, Carolina Acevedo and Nathan D. Burkett-Cadena \\ Florida Medical Entomology Laboratory, Entomology and Nematology Department, University of Florida, \\ 200 9th St. SE, Vero Beach, FL 32962, USA \\ * Correspondence: lereeves@ufl.edu
}

Received: 12 July 2019; Accepted: 30 July 2019; Published: 3 August 2019

check for updates

\begin{abstract}
Characterizing the host-use patterns of mosquitoes is an essential component of understanding the transmission dynamics of mosquito-vectored pathogens. The host associations of two species of the medically important Culex subgenus Melanoconion, Culex atratus, and Culex pilosus are unknown or unclear, respectively. Both species have wide neotropical distributions. In the United States of America (USA), Culex pilosus occurs throughout the southeastern coastal plain, while Culex atratus is restricted to the southern Florida Peninsula. Using PCR-based blood meal analysis, we investigated the host associations of Culex atratus and Culex pilosus that were collected from Everglades National Park, Florida, USA We identified the host species of 208 Culex atratus and 168 Culex pilosus. Both species were narrowly associated with reptilian host species, particularly native and non-native lizards of the genus Anolis. Sampled Culex atratus exclusively fed on reptilian hosts, with $>99 \%$ of blood meals derived from Anolis lizards. Culex pilosus fed predominantly from reptiles, but avian and mammalian blood meals were also detected. Of these, $92 \%$ of blood meals were derived from Anolis species. For both species, Anolis sagrei, an invasive exotic lizard in Florida, was the most frequently detected host species. These data indicate that Culex atratus and Culex pilosus are specialists of reptilian hosts, particularly Anolis lizards.
\end{abstract}

Keywords: Melanoconion; Anolis; Culex; mosquito; blood meal analysis; Florida

\section{Introduction}

The mosquito species that comprise the Culex subgenus Melanoconion are diverse, distributed throughout the Americas, from Canada to Argentina, and are difficult to morphologically distinguish [1]. Of the 160 described Melanoconion species, most are Neotropical in distribution with a center of diversity in the Amazonian Region of northern South America [1]. Ten species of Melanoconion occur in the continental United States of America (USA) and eight of these are present in Florida [2]. Adults and larvae of one, Culex panocossa, were recently collected in southernmost peninsular Florida, and likely represent recent introduction and establishment [3]. Several Melanoconion species are vectors or putative vectors of pathogenic arboviruses. Culex erraticus and Culex taeniopus, for example, transmit eastern equine encephalitis virus [4] and Madariaga virus [5], respectively, while Culex cedecei, Culex iolambdis, Culex taeniopus, and others are enzootic vectors of various Venezuelan equine encephalitis (VEE) virus subtypes $[3,6,7]$. Aside from the known or suspected pathogen vectors, the biology and ecology of the majority of Melanoconion species have not been well characterized. We investigated the host associations of two Melanoconion species in southern Florida, Culex atratus Theobald and Culex pilosus (Dyar \& Knab), both of the Melanoconion Section, Atratus Group and Pilosus Group, respectively [8].

Culex atratus and Cx. pilosus are widely distributed in the American tropics, both being found throughout much of South America [9], the Caribbean [10], and southern North America [2,3]. 
Culex atratus is found throughout northern South America, the Caribbean, and southern Florida, but is not known from Central America, apart from Panama [1,2,11]. Culex pilosus occurs in several states of the southeastern USA, throughout Central America, and as far south as central Argentina [1,12,13]. Few data are available on the host groups fed upon by these mosquitoes despite the very wide distributions of these two mosquito species, and the general importance of Melanoconion species in the transmission of zoonotic arboviruses [11]. Without host associations, it is difficult for arbovirus researchers and public health professionals to "incriminate" or "exonerate" potential vectors species in the transmission of zoonotic pathogens.

Host associations of $C x$. atratus are currently unknown. While some early studies authors $[14,15]$ reported $C x$. atratus to be a major biting nuisance to humans, Page found that few $C x$. atratus females were attracted to human bait [16]. Culex atratus were collected with donkey-baited traps in Jamaica [10], although whether or not donkeys were actually bitten was not reported. In the 1970s, Edman [17] investigated the host associations of Melanoconion mosquitoes from sites in Florida, USA. Notably, $C x$. atratus was absent from Edman's collections in Everglades National Park, where $C x$. atratus has been known to occur since the 1960s $[18,19]$. In Florida, USA, $C x$. atratus is represented by two forms, Culex atratus sensu stricto and Culex atratus B, which are genetically distinct, yet indistinguishable by external morphology [20,21]. The distributions of these two forms and potential differences in their ecologies, which include host associations, are not known.

Host associations of $C x$. pilosus are also unclear, based upon the limited work that has been performed. Edman [17] concluded that $C x$. pilosus predominantly feeds on reptiles in Florida. However, in Louisiana Cupp and Stokes [22] captured female $C x$. pilosus while using dog-baited traps and identified 73 out of $102(71.2 \%)$ Cx. pilosus blood meals, of which, none were derived from reptilian hosts. From these, birds (26.0\%), humans (20.5\%), horses (32.9\%), and dogs (20.5\%) were identified as hosts. In a recent study, Reeves et al. [23] used DNA barcoding to identify five Cx. pilosus blood meals from northern Florida and found four were derived from reptilian hosts and one from an avian host. Otherwise, all previous studies investigating the host-use of $C x$. pilosus relied on the serological methods of host identification that made species-level host identification difficult.

Subgenus Melanoconion is a medically important group of mosquitoes, containing species that are important to the transmission of zoonotic arboviruses. The host associations of two species from Florida, $C x$. atratus and $C x$. pilosus, are not well understood. There are no published blood meal analysis data for $C x$. atratus, and previous work reports contrasting patterns of host use for $C x$. pilosus. We collected the females of $C x$. atratus and $C x$. pilosus from Everglades National Park and surrounding areas in southern Florida and used PCR-based blood meal analysis to investigate and quantify the host use of these two mosquito species.

\section{Materials and Methods}

\subsection{Study Sites and Sampling Protocol}

Mosquitoes were sampled at eight sites in Everglades National Park, Florida, USA and one external site while using resting shelters [24,25] and aspiration of natural resting sites (Table 1). All of the sites were located along State Highway 9336/Main Park Road, between Homestead, Florida, USA and Flamingo, Florida, USA (Figure 1). The external site, the C-111E Canal, was located in a tropical hardwood hammock, which was approximately $5.1 \mathrm{~km}$ from the national park border. Mosquito samples were collected from Everglades National Park between October 2015 and June 2016, and between February 2017 and July 2017 under permit numbers EVER-2015-SCI-0054 and EVER-2017-SCI-0011. The mosquitoes were collected during sampling events lasting two to five consecutive days, every other month. The numbers and placement of resting shelters varied between sampling events. In general, 10-16 shelters (one to two per site) were placed in the field at the beginning of each sampling event and removed at the end of the event. 
Table 1. Sampling localities in and around Everglades National Park, Florida, United States of America (USA) and number of Culex atratus and Culex pilosus blood meals collected and analyzed from each site. All sites are located within the national park with the exception of C-111E Canal.

\begin{tabular}{ccccc}
\hline Nearest Landmark & Habitat & Coordinates & Culex atratus & Culex pilosus \\
\hline C-111E Canal & Hardwood hammock & $25.407291,-80.523353$ & 0 & 2 \\
Anhinga Trail & Hardwood hammock & $25.402178,-80.615617$ & 31 & 85 \\
Long Pine Key & Pine rocklands & $25.399878,-80.659990$ & 27 & 65 \\
Pa-Hay-Okee & Sawgrass prairie & $25.412619,-80.782649$ & 11 & 15 \\
Mahogany Hammock & Hardwood hammock & $25.338870,-80.818099$ & 82 & 34 \\
Nine-Mile Pond & Mangrove & $25.253915,-80.798166$ & 24 & 21 \\
Snake Bight & Mangrove & $25.200773,-80.874253$ & 43 & 12 \\
Buttonwood Canal & Coastal prairie & $25.148854,-80.923344$ & 41 & 11 \\
Flamingo & Coastal prairie & $25.144328,-80.921075$ & 1 & 248 \\
\hline TOTAL & & & 260 & \\
\hline
\end{tabular}

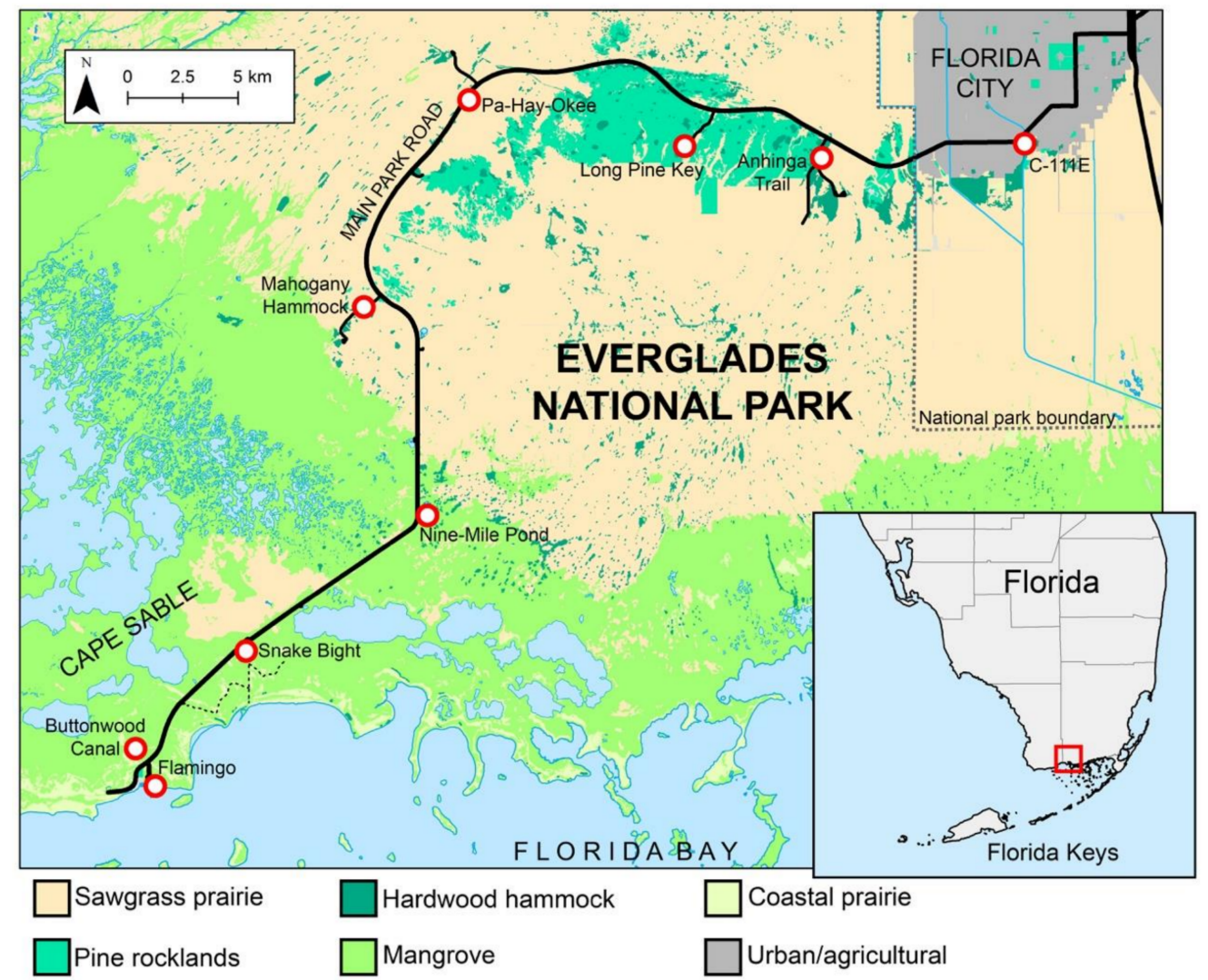

Figure 1. Map of sampling area indicating the sites where blood fed female Culex atratus and Culex pilosus were collected (red circles). The red box in the inset map of the southern Florida Peninsula indicates the figured area.

Mosquitoes were removed from the resting shelters each morning of the sampling event between 0900 and $1100 \mathrm{~h}$ while using a battery-powered aspirator constructed from a Dustbuster ${ }^{\text {TM }}$ (Black \& Decker ${ }^{\circledR}$, Towson, MD, USA) handheld vacuum modified to hold plastic collection canisters with wire mesh bottoms (BioQuip Products, Rancho Dominguez, CA, USA), as described in Bingham et al. [26]. Various methods were used to minimize the escape of resting mosquitoes during collection including using baffles $[23,24]$. The same aspirators were used to collect mosquitoes from natural resting sites (e.g., root masses of fallen trees, bases of tree trunk, tree cavities, dense vegetation). The aspirator, powered on, was swept through natural resting sites at 5-10 min. intervals. The use of this method varied between sites and sampling events due to the availability and accessibility of natural resting sites. 
Immediately following collection, mosquitoes in collection canisters were either transported alive on ice inside a cooler to Flamingo (at the southern terminus of State Highway 9336/Main Park Road), or maintained on dry ice for two to three days until transportation to the Florida Medical Entomology Laboratory, Vero Beach, Florida, USA. At Flamingo, the mosquitoes were killed by exposure to ethyl acetate-soaked plaster for $\sim 10 \mathrm{~min}$. and examined under stereoscope magnification. Any female mosquito with visible evidence of blood in its abdomen was separated, being identified to species level [12], and preserved on Whatman ${ }^{\circledR}$ four-sample Flinders Technology Associates (FTA) Classic Cards [27]. Each mosquito was assigned a unique identifying number and transferred to the sampling area of the FTA card. The apical end of a sterile pipette tip was placed between the thorax and the abdomen of the mosquito, and pressure was gently applied to release the blood meal onto the card. The blood meal was spread around the sampling area of the card until all of the viscous droplets were absorbed. The preserved blood meals were air-dried for $\sim 10 \mathrm{~min}$. and stored in plastic bags until DNA extraction. Mosquitoes transported to the Florida Medical Entomology Laboratory were maintained frozen $\left(-20^{\circ} \mathrm{C}\right)$ until morphological identification while using a chill table.

\subsection{Blood Meal Analysis}

DNA was directly extracted from blood meals preserved on FTA cards while using the hot sodium hydroxide and tris (HotSHOT) method [28] or from whole mosquito specimens. The DNA extraction protocol for FTA card-preserved mosquito blood meals, followed a previously published protocol [27]. Two $1 \mathrm{~mm}$ sections of each blood meal were removed from the card with a $1 \mathrm{~mm}$ hole punch. The punches were transferred to the same $0.2 \mathrm{~mL}$ PCR tube or $0.2 \mathrm{~mL}$ well of a 96-well PCR plate while using flame-sterilized forceps and $25 \mu \mathrm{L}$ of lysis solution ( $25 \mathrm{mM} \mathrm{NaOH}$ and $0.2 \mathrm{mM}$ EDTA) were added. The tubes/plate were sealed and incubated at $95^{\circ} \mathrm{C}$ for $30 \mathrm{~min}$., followed by $4{ }^{\circ} \mathrm{C}$ for five min. in a BioRad DNA Engine thermocycler. Following incubation, $25 \mu \mathrm{L}$ of neutralization solution $(40 \mathrm{mM}$ Tris- $\mathrm{HCl})$ were added to each tube/well. The samples were briefly vortexed and stored at -20 ${ }^{\circ} \mathrm{C}$ until PCR. DNA was extracted from whole mosquito specimens using Instagene Matrix or Chelex resin (BioRad, Hercules, CA, USA) while using published protocols [29-31].

Extracted DNA was used as DNA template in PCRs that were intended to amplify regions of the vertebrate cytochrome $c$ oxidase subunit I (COI) gene or 16S ribosomal RNA gene while using four primer pairs (Table 2). Host identifications using the vertebrate COI gene used an unstructured hierarchical approach and the primer sets described in Reeves et al. [32]. Briefly, DNA extracted from mosquito blood meals were used as templates in PCR reactions while using one of three primer sets: VertCOI_7194_F and Mod_RepCOI_R (expected amplicon length 395 bp), Mod_RepCOI_F and VertCOI_7216_R (244 bp), and Mod_RepCOI_F and Mod_RepCOI_R (664 bp). The products of successful amplification reactions were sequenced. DNA templates that failed to amplify were subsequently used in a second reaction with a different primer set, and products were sequenced if amplification was successful. If amplification failed, the template was used in a third reaction, while using the remaining primer set. If the third reaction did not produce an amplicon, no further steps were taken, and the blood meal was not identified.

For all reactions intended to amplify vertebrate COI templates, other than the primer sequence, the thermocycling conditions, reagents, and reagent concentrations were identical for all amplification reactions. Each reaction followed the protocol of Reeves et al. [32] and each was performed in a total volume of $20 \mu \mathrm{L}$ that consisted of $10 \mu \mathrm{L}$ of 2.0X ApexTM Taq RED Master Mix ${ }^{\circledR}$ (Genesee Scientific, San Diego, CA, USA), $0.75 \mu \mathrm{L}$ forward primer $(10 \mu \mathrm{M}), 0.75 \mu \mathrm{L}$ reverse primer $(10 \mu \mathrm{M}), 7.5 \mu \mathrm{L}$ sterile, double-distilled water, and $1 \mu \mathrm{L}$ of extracted DNA. Thermocycling conditions followed a standard profile for all reactions that consisted of an initial denaturing step of $94^{\circ} \mathrm{C}$ for $3 \mathrm{~min}$., followed by 40 cycles of $94{ }^{\circ} \mathrm{C}$ for $40 \mathrm{~s}, 48.5^{\circ} \mathrm{C}$ for $30 \mathrm{~s}$, and $72{ }^{\circ} \mathrm{C}$ for $60 \mathrm{~s}$, and a final extension step of $72{ }^{\circ} \mathrm{C}$ for $7 \mathrm{~min}$. 
Table 2. Primer pairs used to amplify vertebrate host DNA from Culex atratus and Culex pilosus blood meals that were collected in southern Florida, USA.

\begin{tabular}{|c|c|c|c|c|}
\hline Primer Name & Gene & Primer Sequence & Amplicon Size (bp) & Reference \\
\hline VertCOI_7194_F & \multirow[t]{2}{*}{ COI } & 5'-CGM ATR AAY AAY ATR AGC TTC TGA Y-3' & \multirow[t]{2}{*}{395} & \multirow[t]{2}{*}[32]{} \\
\hline Mod_RepCOI_R & & 5'-TTC DGG RTG NCC RAA RAA TCA-3' & & \\
\hline Mod_RepCOI_F & \multirow[t]{2}{*}{ COI } & 5'-TNT TYT CMA CYA ACC ACA AAG A-3' & \multirow[t]{2}{*}{244} & \multirow[t]{2}{*}[32]{} \\
\hline VertCOI_7216_R & & 5'-CAR AAG CTY ATG TTR TTY ATD CG-3' & & \\
\hline Mod_RepCOI_F & \multirow[t]{2}{*}{ COI } & 5'-TNT TYT CMA CYA ACC ACA AAG A-3' & \multirow[t]{2}{*}{664} & \multirow[t]{2}{*}[32]{} \\
\hline Mod_RepCOI_R & & 5'-TTC DGG RTG NCC RAA RAA TCA-3' & & \\
\hline 16L1 & \multirow[t]{2}{*}{$16 \mathrm{~s}$} & 5'-CTGACCGTGCAAAGGTAGCGTAATCACT-3' & \multirow[t]{2}{*}{450} & \multirow[t]{2}{*}{ [29-31] } \\
\hline Н3056 & & 5'-CTCCGGTCTGAACTCAGATCACGTAGG-3' & & \\
\hline
\end{tabular}


Reactions that were intended to amplify vertebrate $16 \mathrm{~s}$ templates followed previously published protocols [29-31] and were performed in a total volume of $25 \mu \mathrm{L}$ that consisted of $0.625 \mu \mathrm{L}$ of forward primer 16L1 $(20 \mu \mathrm{M}), 0.625 \mu \mathrm{L}$ of reverse primer H3056 $(20 \mu \mathrm{M}), 2.5 \mu \mathrm{L} 10 \times$ PCR buffer, $1.5 \mu \mathrm{L} \mathrm{MgCl}_{2}$ (50 mM), $2.5 \mu \mathrm{L}$ dNTP mix ( $2 \mathrm{mM}$ each), $0.5 \mu \mathrm{L}$ Taq DNA polymerase, $2.5 \mu \mathrm{L}$ DNA template, and $14.25 \mu \mathrm{L}$ molecular grade water. Thermocycling conditions for all reactions targeting $16 \mathrm{~s}$ templates consisted of $4 \mathrm{~min}$. at $95{ }^{\circ} \mathrm{C}, 35$ cycles of $95^{\circ} \mathrm{C}$ for $30 \mathrm{~s}, 62.5^{\circ} \mathrm{C}$ for $30 \mathrm{~s}, 72{ }^{\circ} \mathrm{C}$ for $30 \mathrm{~s}$ and a final extensions step of $72{ }^{\circ} \mathrm{C}$ for $7 \mathrm{~min}$.

Negative controls in which sterile double-distilled water replaced extracted DNA were included in all of the reactions to monitor for contamination. The reaction products were stained with ethidium bromide, electrophoresed on a 1.5\% agarose gel for approximately $30 \mathrm{~min}$., and visualized under ultra-violet light. A $50 \mathrm{bp}$ DNA ladder was electrophoresed alongside PCR products to estimate the size of any visible amplicons. Products from all reactions that showed the presence of an amplicon of the expected size were sent to Genewiz ${ }^{\circledR}$ (South Plainfield, NJ, USA) or Eurofins ${ }^{\circledR}$ (Louisville, KY, USA) for purification and DNA sequencing via the Sanger method [33].

Sequence files from positive reactions were checked and edited for quality while using the bioinformatics software Geneious version R10 [34]. Sequences were then submitted to the Barcode of Life Datasystems [35] sequence database for identification. Sequences that were $>98 \%$ similar to referenced sequences, or independently obtained reference sequences $[23,32]$ were identified as the corresponding species.

\subsection{Statistical Analysis}

Fisher's exact test [36] was used to test for differences in the effect of primer pair on blood meal results. Separate analyses were performed for $C x$. atratus and $C x$. pilosus, while using the count of blood meals attributed to each host class or that did not amplify as the dependent variable. Fisher's exact test was selected to assess whether the relative proportions of blood meal analysis results were similar across the primer sets, because the expected numbers for some categories were small.

\section{Results}

We collected and analyzed blood meals from a total of 260 Cx. atratus and 248 Cx. pilosus (Table 3). Blood meal analysis successfully identified a host species for $208(80 \%)$ Cx. atratus and $168(67.7 \%)$ $C x$. pilosus. Amplification was successful for $81.4 \%$ of $C x$. atratus and $67.7 \%$ of $C x$. pilosus samples attempted. One $C x$. pilosus blood meal was derived from more than one host species. The blood meal analysis results across primer sets and the distribution of host class counts for each primer set were relatively even. Fisher's exact test indicated that there were no differences in the effect of primer set on blood meal analysis results for Culex atratus $(p=0.446)$ and Culex pilosus $(p=0.79)$.

From the $208 C x$. atratus blood meals that were successfully identified, just three species of vertebrate hosts were detected. Two lizard species of the genus Anolis, Anolis sagrei (brown anole) and Anolis carolinensis (green anole) were the most frequently detected hosts, together representing 99\% of identified $C x$. atratus blood meals (Figure 2). Of these, 163 blood meals $(78.4 \%$ ) were attributed to A. sagrei, and $43(20.7 \%)$ were attributed to A. carolinensis. Only two $C x$. atratus blood meals were identified from other host species, both from Alligator mississippiensis (American alligator). Fifty-two $C x$. atratus blood meals were not amplified by PCR.

The host-use patterns of $C x$. pilosus were similar to those of $C x$. atratus, but with greater host breadth (Figure 1). Anolis lizards were the most frequently detected hosts $(92.2 \%$, together). In addition to A. sagrei and A. carolinensis, one blood meal, from the C-111E Canal site, was derived from Anolis equestris (knight anole). Anolis sagrei and A. carolinensis were the first and second most frequently identified host species, representing $81.5 \%$ and $10.7 \%$ of all identified blood meals, respectively. Altogether, twelve host species were detected from the sample of 168 identified $C x$. pilosus blood meals. Nine other vertebrate host species were detected in addition to the three Anolis species, each with $<3$ detections. These species were primarily reptiles, including species of snakes, turtles, and crocodilians, but three 
were endothermic hosts: Cardinalis cardinalis (northern cardinal), Nyctanassa violacea (yellow-crowned night heron), and Homo sapiens.

Table 3. Results of blood meal analysis for Culex atratus and Culex pilosus from southern Florida. For each mosquito species the number (n) of blood meals derived from each host species, and the percentage (\%) of identified blood meals attributed to each host are indicated. Mixed blood meals refer to blood meals derived from more than one host animal. No amplification refers to blood meals that did not produce a PCR amplicon, and as a result were not identified.

\begin{tabular}{cccccc}
\hline \multirow{2}{*}{ Host Class } & Host Species & \multicolumn{2}{c}{ Culex atratus } & \multicolumn{2}{c}{ Culex pilosus } \\
\cline { 3 - 6 } & & $\mathbf{n}$ & $\mathbf{\%}$ & $\mathbf{n}$ & $\%$ \\
\hline Reptilia & Anolis carolinensis & 43 & 20.6 & 18 & 10.7 \\
Reptilia & Anolis sagrei & 163 & 78 & 137 & 81.5 \\
Reptilia & Anolis equestris & 0 & 0 & 1 & 0.6 \\
Reptilia & Coluber constrictor & 0 & 0 & 1 & 0.6 \\
Reptilia & Nerodia fasciata & 0 & 0 & 1 & 0.6 \\
Reptilia & Alligator mississippiensis & 2 & 1 & 2 & 1 \\
Reptilia & Crocodylus acutus & 0 & 0 & 3 & 1.7 \\
Reptilia & Terrapene carolina & 0 & 0 & 1 & 0.6 \\
Amphibia & Hyla cinerea & 0 & 0 & 1 & 0.6 \\
Aves & Cardinalis cardinalis & 0 & 0 & 1 & 0.6 \\
Aves & Nyctanassa violacea & 0 & 0 & 1 & 0.6 \\
Mammalia & Homo sapiens & 0 & 0 & 1 & 0.6 \\
& Mixed blood meal & 0 & 0 & 1 & 0.6 \\
& No amplification & 52 & & 80 & \\
\hline & Total identified & 208 & & 168 & \\
\hline
\end{tabular}

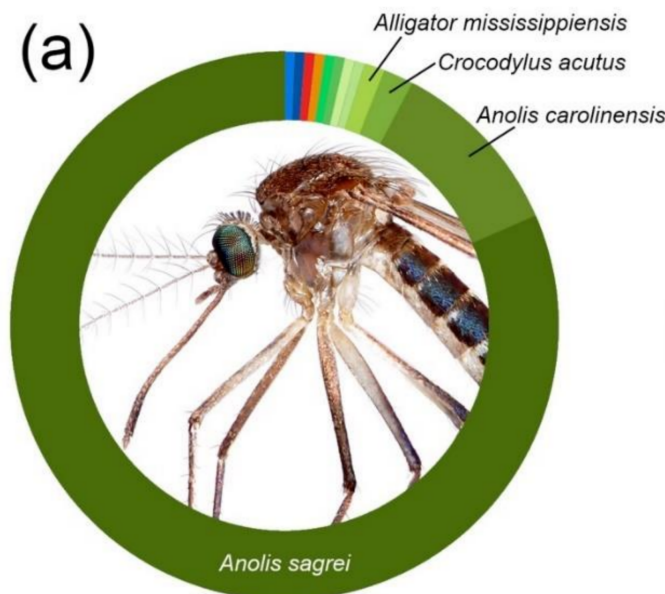

Culex pilosus $(\mathrm{n}=168)$
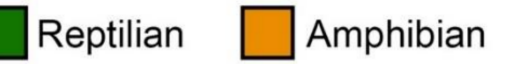

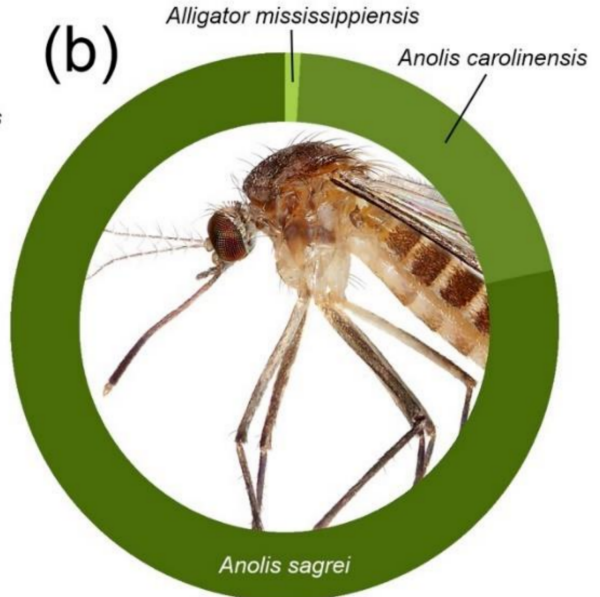

Culex atratus $(\mathrm{n}=208)$

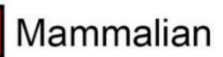

Avian

Figure 2. Composition of hosts identified from samples of (a) Culex pilosus and (b) Culex atratus blood meals collected in Everglades National Park, Florida USA by host class. Colors (green, orange, red, blue) indicate host class. Shades of each color indicate host species within each respective class. Host species represented by $>1$ blood meal are labeled.

\section{Discussion}

The blood meal analysis results of the current study indicated that $C x$. atratus and $C x$. pilosus are strongly associated with reptilian hosts, particularly lizards of the genus Anolis, at Everglades 
National Park (Figure 3). This provides the first documented host associations of Cx. atratus by blood meal analysis, which suggested that previous indications of $C x$. atratus posing a biting nuisance to humans $[14,15]$ could be due to misidentifications. These results also provide support for the conclusions of Edman [17] and Reeves et al. [23] that Cx. pilosus predominantly feeds on reptiles.

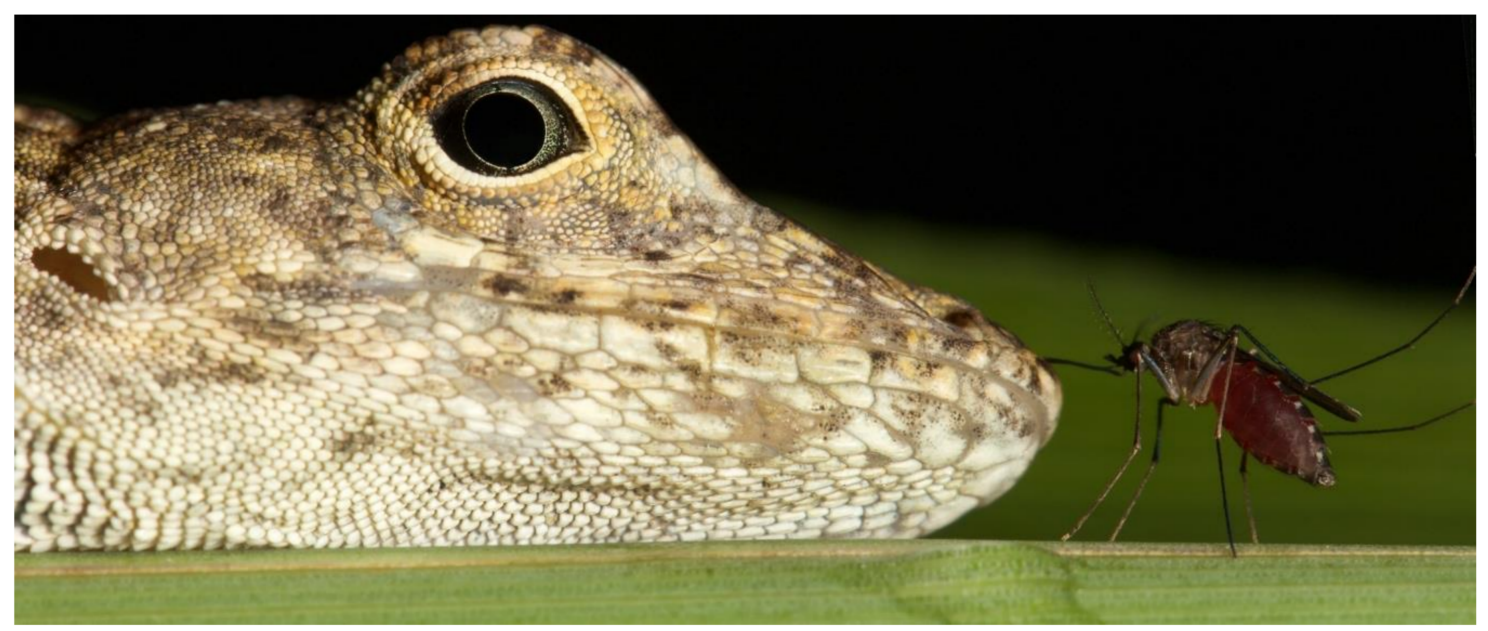

Figure 3. Female Culex pilosus feeding from Anolis sagrei at Blue Cypress Lake, Indian River County, Florida, USA, 8 July 2018.

For Cx. atratus and Cx. pilosus, $20 \%$ and $32 \%$ of blood meals, respectively, did not to produce a PCR amplicon. We expect this is due to mosquito digestion-associated degradation of template host DNA. Previous investigations have found that host DNA becomes undetectable by PCR after 36-72 h post-feeding [27]. Following collection of specimens, all of the mosquitoes that contained a visible trace of a blood meal were included in the sample, and it is likely that a portion of the collected blood meals were beyond this host DNA detection timeframe. It is also possible that this timeframe varies between host classes. The red blood cells of mammals are anucleated and they do not contain mitochondria, while those of amphibians, birds, and at least some reptiles are nucleated and contain mitochondria [37]. Our molecular analyses targeted mitochondrial genes that, as a result, are likely more abundant in non-mammalian blood. The impact of this on blood meal analyses that target mitochondrial DNA is unknown, but previous research using the same primer sets effectively identified the mammalian hosts from mosquito blood meals [29-32].

We found Cx. atratus to be abundant in sites throughout Everglades National Park (Table 1, [25]). We observed that mosquitoes were generally less abundant in resting shelter and aspirator collections when the environmental conditions were dry or windy, or when temperatures were low. Cx. atratus and Cx. pilosus were both common in most sampled habitats (Table 1), but generally more mosquitoes were collected from more complex habitats with increased tree cover (e.g., tropical hardwood hammocks, pine rocklands, and to a lesser extent, mangroves). Future work should explore the environmental and climatic factors that influence activity, abundance, and host associations of these mosquitoes over time in southern Florida. Our finding that $C x$. atratus is abundant in Everglades National Park conflicts with the results of Edman [17], despite the use of similar collection methods (resting shelters and aspiration of natural resting sites). The discrepancy in abundance between our current work and that of Edman [17], in which $C x$. atratus was not encountered, might be due to the introduction, establishment and dispersal of (1) an important host (A. sagrei); or, (2) an exotic cryptic species of Cx. atratus.

Culex atratus blood meals were derived from an especially narrow range of host animals, with 99\% of all identified blood meals being obtained from two Anolis species. Of these, $79 \%$ of blood meals were from just one species, A. sagrei. Anolis sagrei is now one of the most abundant reptile species in Florida, occurring in every county of the peninsula [38]. It is possible that the establishment of Anolis sagrei in Florida enabled $C x$. atratus to expand its distribution and increase its abundance in 
the southern half of the state. The exact timing of the establishment and expansion of $A$. sagrei in the Everglades is difficult to determine, but, by 1980, A. sagrei was well established in urban areas of the Florida Peninsula [38], subsequent to the work of Edman [17]. Anolis sagrei is native to Cuba and the Bahamas and it has been widely introduced outside its native range [39].

Florida populations of $C x$. atratus represent two putative cryptic species, Culex atratus s.s. and an undescribed species, Culex atratus B [20]. The external morphologies of these putative species are identical, but they are distinguishable by DNA sequence variation and the morphology of the cibarial armature [20]. We dissected and prepared the heads and cibarial armature of a subset of Culex atratus sensu latu collected at Everglades National Park during the sampling period. These individuals were consistently identified as $C x$. atratus B. Further work is required for understanding the distribution of $C x$. atratus s.s. and $C x$. atratus $B$ in Florida, and to identify the differences in host associations, if any. It is possible that the distribution of $C x$. atratus $B$ has expanded northward, as suggested by recent new county records from Vero Beach, Indian River County [29].

If the availability of certain primary hosts is a prerequisite for $C x$. atratus and $C x$. pilosus, the presence of Anolis lizards may be a factor in their geographic occurrence. The USA distribution of $C x$. atratus is entirely sympatric with both $A$. sagrei and A. carolinensis, and the collection records suggest that it is limited to coastal regions of the southern Florida Peninsula, as far north as Indian River [29] and Manatee County [40]. Like Cx. atratus, the primary hosts of $C x$. pilosus were A. sagrei and A. carolinensis. The USA distribution of $C x$. pilosus extends beyond that of $A$. sagrei, and it loosely parallels the distribution of $A$. carolinensis [2,41]. The host associations of $C x$. pilosus differed from those of $C x$. atratus in that $\sim 10 \%$ of $C x$. pilosus blood meals were derived from non-Anolis hosts. These hosts were largely reptilian, but avian and mammalian hosts were also detected. In comparison, $<1 \%$ of $C x$. atratus blood meals were derived from non-Anolis host animals. The determinants of geographic distribution for these mosquitoes are unclear, but a greater flexibility of host associations might enable $C x$. pilosus to occupy a wider range in the USA Similarly, the spread of non-native species, such as A. sagrei, which are primary hosts for mosquito species may influence the geographic distribution of mosquitoes and enable them to expand their range.

Overall, and at each site, A. sagrei was fed upon more frequently than A. carolinensis by both mosquito species. This result may reflect the abundance patterns of the two Anolis species. Alternatively, host-seeking and foraging behavior by the mosquitoes may influence the strength of the host associations of these mosquitoes. Anolis sagrei and A. carolinensis occupy similar ecological niches, and one result of interspecific competition between these species in Florida is niche partitioning [42]. In habitats that are occupied by both $A$. sagrei and $A$. carolinensis, the species are vertically stratified with $A$. sagrei occupying ground and understory microhabitats, and A. carolinensis shifting to the canopy and higher microhabitats $[43,44]$. If female $C x$. atratus and $C x$. pilosus concentrate their host-seeking activity to the lower levels of their habitats, they may be more likely to encounter A. sagrei rather than A. carolinensis, which potentially leads to the host association patterns that we observed.

In general, the host associations of Melanoconion mosquitoes are poorly known, and for the majority of species of this diverse group, remain uncharacterized. Among those for which blood meal analysis data are available, a range of host associations have been identified. These data suggest that some Melanoconion species (e.g., Cx. iolambdis, Cx. erraticus) are generalists that feed from a broad range of hosts, including all terrestrial vertebrate classes [17,29,45-47]. Others primarily feed from mammals (e.g., Cx. cedecei, Culex paracrybda) with varying extents of specialization for particular orders $[17,30,43,48]$. At least one, Culex peccator, feeds broadly on ectothermic hosts (reptiles and amphibians), with no particularly strong association with lizards [47,49]. Tempelis and Galindo [48] and Christensen et al. [45] investigated the host use patterns of mosquitoes in Panama while using serological methods, and found that several Melanoconion species (Culex conspirator, Culex dunni, Culex educator, Culex elevator, Culex egcymon) fed primarily from lizards, although not as narrowly as $C x$. atratus and $C x$. pilosus in the current study. 
In Florida, and elsewhere in the Neotropics, Melanoconion mosquitoes are important vectors of VEE virus [6]. Edman [17] stated that "Even though engorged $C x$. atratus and [Culex] mulrennani were not encountered and tested in this investigation, their importance in VEE transmission can be safely eliminated on grounds of distribution and abundance". Recent work indicates that $C x$. atratus is a common mosquito in Everglades National Park [25] and occurs further north than previously known [29]. Either $C x$. atratus was present but undetected by Edman [17] in the Everglades, or its distribution and abundance patterns have since shifted. Our results suggest that host associations, rather than distribution and abundance, exonerate $C x$. atratus as a potential vector of VEE virus. Similarly, the vector of Plasmodium floridense, which is a saurian malaria parasite that infects A. carolinensis, A. sagrei, and Sceloporus undulatus (eastern fence lizard) in Florida [50,51], is unknown but presumed to be $C x$. erraticus [52]. Although $C x$. erraticus has been found to feed from reptilian (though not lizard) hosts in the southeastern USA, previous work indicates that it more frequently feeds from endothermic hosts, with blood meal analyses finding $2-7 \%$ of tested blood meals derived from reptiles $[17,47,49,53]$. In comparison, we found that reptiles, particularly Anolis lizards, made up $99.5 \%$ and $97.6 \%$ of all identified $C x$. atratus and $C x$. pilosus blood meals, respectively. Given the strong association that we observed between Anolis lizards and $C x$. atratus and $C x$. pilosus, these mosquitoes should be further investigated as potential vectors of Plasmodium floridense.

\section{Conclusions}

In Everglades National Park, Florida, $C x$. atratus and $C x$. pilosus were strongly associated with reptilian hosts, particularly native and non-native lizards of the genus Anolis. The host associations of $C x$. atratus were previously unknown, and those of $C x$. pilosus were unclear. Previous investigations of $C x$. pilosus found diverging patterns of host-use. Our results, which are based on blood meal analysis from 260 Cx. atratus and 248 Cx. pilosus from multiple sites in Everglades National Park indicate that, in southern Florida, these mosquito species are specialists of reptilian hosts, particularly Anolis lizards.

Author Contributions: Conceptualization, N.D.B.-C. and L.E.R.; methodology, N.D.B.-C. and L.E.R.; software, N.D.B.-C. and L.E.R.; validation, N.D.B.-C. and L.E.R.; formal analysis, N.D.B.-C. and L.E.R.; investigation, I.H., C.A., N.D.B.-C. and L.E.R.; resources, N.D.B.-C. and L.E.R.; data curation, N.D.B.-C. and L.E.R.; writing-original draft preparation, N.D.B.-C. and L.E.R.; writing—review and editing, I.H., C.A., N.D.B.-C. and L.E.R.; visualization, N.D.B.-C. and L.E.R.; supervision, N.D.B.-C.; project administration, N.D.B.-C. and L.E.R.; funding acquisition, N.D.B.-C. and L.E.R.

Funding: This material is based upon work supported by the National Science Foundation Graduate Research Fellowship under Grant No. 00107251 to L.E.R, and IFAS Early Career Scientist Seed Grant and NIFA FLA-VME-005446 to N.D.B.-C.

Acknowledgments: We thank P.J. Walker and the National Park Service for granting permits to conduct research in Everglades National Park, Chase Kimmel and Kristin Sloyer for GIS assistance, and Phillip E. Kaufman for providing laboratory and freezer space.

Conflicts of Interest: The authors declare no conflict of interest. The funders had no role in the design of the study; in the collection, analyses, or interpretation of data; in the writing of the manuscript, or in the decision to publish the results.

\section{References}

1. Torres-Gutierrez, C.; Sallum, M.A.B. Catalog of the subgenus Melanoconion of Culex (Diptera: Culicidae) for South America. Zootaxa 2014, 4028, 1-50. [CrossRef] [PubMed]

2. Darsie, R.F.; Ward, R.A. Identification and Geographical Distribution of the Mosquitoes of North America, North of Mexico; University Press of Florida: Gainesville, FL, USA, 2005; p. 384.

3. Blosser, E.M.; Burkett-Cadena, N.D. Culex (Melanoconion) panocossa from peninsular Florida, USA. Acta Trop. 2017, 167, 59-63. [CrossRef] [PubMed]

4. Bingham, A.M.; Burkett-Cadena, N.D.; Hassan, H.K.; Unnasch, T.R. Vector competence and capacity of Culex erraticus (Diptera: Culicidae) for eastern equine encephalitis virus in the southeastern United States. J. Med. Entomol. 2015, 53, 473-476. [CrossRef] [PubMed] 
5. Vittor, A.Y.; Armien, B.; Gonzalez, P.; Carrera, J.-P.; Dominguez, C.; Valderrama, A.; Glass, G.E.; Beltran, D.; Cisneros, J.; Wang, E.; et al. Epidemiology of emergent Madariaga encephalitis in a region with endemic Venezuelan equine encephalitis: Initial host studies and human cross-sectional study in Darien, Panama. PLoS Negl. Trop. Dis. 2016, 10, e0004554. [CrossRef] [PubMed]

6. Weaver, S.C.; Ferro, C.; Barrera, R.; Boshell, J.; Navarro, J.C. Venezuelan equine encephalitis. Annu. Rev. Entomol. 2004, 49, 141-174. [CrossRef]

7. Coffey, L.L.; Weaver, S.C. Susceptibility of Ochlerotatus taeniorhynchus and Culex nigripalpus for Everglades virus. Am. J. Trop. Med. Hyg. 2005, 73, 11-16. [CrossRef]

8. Harbach, R.E. Classification within the cosmopolitan genus Culex (Diptera: Culicidae): The foundation for molecular systematics and phylogenetic research. Acta Trop. 2011, 120, 1-14. [CrossRef]

9. Lane, J. Neotropical Culicidae, Vols. I and II; University of São Paulo: São Paulo, Brazil, 1953; p. 112.

10. Belkin, J.N.; Heinemann, S.J.; Page, W.A. The Culicidae of Jamaica (Mosquito studies XXI). Contrib. Am. Entomol. Inst. 1970, 6, 1-319.

11. Pecor, J.E.; Mallampalli, V.L.; Harbach, R.E.; Peyton, E.L. Catalog and illustrated review of the subgenus Melanoconion of Culex (Diptera: Culicidae). Contrib. Am. Entomol. Inst. 1992, 27, 1-234.

12. Darsie Jr., R.F.; Morris, C.D. Keys to the Adult Females and Fourth Instar Larvae of the Mosquitoes of Florida (Diptera, Culicidae); Florida Mosquito Control Association: Lehigh Acres, FL, USA, 2003; p. 156.

13. Urcola, J.I.; Fischer, S. First record and larval habitat description of Culex (Melanoconion) pilosus from Buenos Aires Province, Argentina. J. Am. Mosq. Control Assoc. 2015, 31, 271-274. [CrossRef]

14. Grabham, M. Notes on some new mosquitoes from Jamaica, West Indies. Can. Entomol. 1907, 39, 25-26. [CrossRef]

15. Hill, R.B.; Hill, C.M. The mosquitoes of Jamaica. Bull. Inst. Jam. 1948, 4, 1-60.

16. Page, W.A. Observations on man-biting mosquitoes in Jamaica. In Proceedings of the Royal Entomological Society of London; Series A, General Entomology. Blackwell Publishing Ltd.: Oxford, UK, 1967; Volume 42, pp. 180-186.

17. Edman, J.D. Host-feeding patterns of Florida mosquitoes (Diptera: Culicidae) VI. Culex (Melanoconion). J. Med. Entomol. 1979, 15, 521-525. [CrossRef]

18. Chamberlain, R.W.; Sudia, W.D.; Coleman, P.H.; Work, T.H. Venezuelan equine encephalitis virus from south Florida. Science 1964, 17, 272-274. [CrossRef]

19. Chamberlain, R.W.; Sudia, W.D.; Work, T.H.; Coleman, P.H.; Newhouse, V.F.; Johnston, J.G., Jr. Arbovirus studies in south Florida, with emphasis on Venezuelan equine encephalomyelitis virus. Am. J. Epidemiol. 1969, 89, 197-210. [CrossRef]

20. Williams, M.R.; Savage, H.M. Identification of Culex (Melanoconion) species of the United States using female cibarial armature (Diptera: Culicidae). J. Med. Entomol. 2009, 46, 745-752. [CrossRef]

21. Williams, M.R.; Savage, H.M. Development of multiplexed species specific polymerase chain reaction assays for identification of the Culex (Melanoconion) species (Diptera: Culicidae) of the southeastern United States based on rDNA. J. Med. Entomol. 2011, 48, 961-966. [CrossRef]

22. Cupp, E.W.; Stokes, G.M. Identification of blood meals from mosquitoes collected in light traps and dog baited traps. Mosq. News 1973, 33, 39-41.

23. Reeves, L.E.; Krysko, K.L.; Avery, M.L.; Gillett-Kaufman, J.L.; Kawahara, A.Y.; Connelly, C.R.; Kaufman, P.E. Interactions between the invasive Burmese python, Python bivittatus Kuhl, and the local mosquito community in Florida, USA. PLoS ONE 2018, 13, e0190633. [CrossRef]

24. Burkett-Cadena, N.D. A wire-frame shelter for collecting resting mosquitoes. J. Am. Mosq. Control Assoc. 2011, 27, 153-155. [CrossRef]

25. Burkett-Cadena, N.D.; Hoyer, I.; Blosser, E.; Reeves, L.E. Human-powered pop-up resting shelter for sampling cavity-resting mosquitoes. Acta Trop. 2019, 190, 288-292. [CrossRef]

26. Bingham, A.M.; Burkett-Cadena, N.D.; Hassan, H.K.; McClure, C.J.W.; Unnasch, T.R. Field investigations of winter transmission of Eastern equine encephalitis virus in Florida. Am. J. Trop. Med. Hyg. 2014, 91, 685-693. [CrossRef]

27. Reeves, L.E.; Holderman, C.J.; Gillett-Kaufman, J.L.; Kawahara, A.Y.; Kaufman, P.E. Maintenance of host DNA integrity in field-preserved mosquito (Diptera: Culicidae) blood meals for identification by DNA barcoding. Parasit. Vectors 2016, 9, 503. [CrossRef] 
28. Truett, G.E.; Heeger, P.; Mynatt, R.L.; Truett, A.A.; Walker, J.A.; Warman, M.L. Preparation of PCR quality mouse genomic DNA with sodium hydroxide and Tris (HotSHOT). Biotechniques 2000, 29, 52-54. [CrossRef]

29. Blosser, E.M.; Stenn, T.; Acevedo, C.; Burkett-Cadena, N.D. Host use and seasonality of Culex (Melanoconion) iolambdis (Diptera: Culicidae) from eastern Florida, USA. Acta Trop. 2016, 164, 352-359. [CrossRef]

30. Hoyer, I.J.; Blosser, E.M.; Acevedo, C.; Thompson, A.C.; Reeves, L.E.; Burkett-Cadena, N.D. Mammal decline, linked to invasive Burmese python, shifts host use of vector mosquito towards reservoir hosts of a zoonotic disease. Biol. Lett. 2017, 13, 20170353. [CrossRef]

31. Hoyer, I.J.; Acevedo, C.; Wiggins, K.; Alto, B.W.; Burkett-Cadena, N.D. Patterns of abundance, host use, and Everglades virus infection in Culex (Melanoconion) cedecei mosquitoes, Florida, USA. Emerg. Infect. Dis. 2019, 25, 1093-1100. [CrossRef]

32. Reeves, L.E.; Gillett-Kaufman, J.L.; Kawahara, A.Y.; Kaufman, P.E. Barcoding blood meals: New vertebratespecific primer sets for assigning taxonomic identities to host DNA from mosquito blood meals. PLoS Negl. Trop. Dis. 2018, 12, e0006767. [CrossRef]

33. Sanger, F.; Nicklen, S.; Coulson, A.R. DNA sequencing with chain-terminating inhibitors. Proc. Natl. Acad. Sci. USA 1977, 74, 5463-5467. [CrossRef]

34. Kearse, M.; Moir, R.; Wilson, A.; Stones-Havas, S.; Cheung, M.; Sturrock, S. Geneious Basic: An integrated and extendable desktop software platform for the organization and analysis of sequence data. Bioinformatics 2012, 28, 1647-1649. [CrossRef]

35. Ratnasingham, S.; Hebert, P.D.N. BOLD: The Barcode of Life Data System (www.barcodinglife.org). Mol. Ecol. Notes 2007, 7, 355-364. [CrossRef]

36. Fisher, R.A. Statistical Methods for Research Workers; Oliver and Boyd: Edinburgh, UK, 1932.

37. Ogo, S.H.; Bernardes, C.F.; Glass, M.L.; Torsoni, M.A.; Vercesi, A.E. Functional mitochondria in snake Bothrops alternus erythrocytes and modulation of $\mathrm{HbO}_{2}$ affinity by mitochondrial ATP. J. Comp. Physiol. B 1993, 163, 614-619. [CrossRef]

38. Krysko, K.L.; Enge, K.M.; Moler, P.E. Atlas of Amphibians and Reptiles in Florida; Florida Fish and Wildlife Conservation Commission: Tallahassee, FL, USA, 2011; p. 524.

39. Stroud, J.T.; Richardson, A.J.; Sim, J.; Airnes, A. Onward to the Mid-Atlantic: First records of Cuban brown anoles (Anolis sagrei) on Ascension Island. Reptiles Amphib. 2018, 25, 220-222.

40. Branch, N.; Logan, L.; Beck, E.C.; Mulrennan, J.A. New distributional records for Florida mosquitoes. Fla. Entomol. 1958, 41, 155-163. [CrossRef]

41. Campbell-Staton, S.C.; Goodman, R.M.; Backstrom, N.; Edwards, S.V.; Losos, J.B.; Kolbe, J.J. Out of Florida: mtDNA reveals patterns of migration and Pleistocene range expansion of the green anole lizard (Anolis carolinensis). Ecol. Evol. 2012, 2, 2274-2284. [CrossRef]

42. Kamanth, A.; Stuart, Y.E.; Campbell, T.S. Behavioral partitioning by the native lizard Anolis carolinensis in the presence and absence of the invasive Anolis sagrei in Florida. Breviora 2013, 535, 1-10. [CrossRef]

43. Edwards, J.R.; Lailvaux, S.P. Display behavior and habitat use in single and mixed populations of Anolis carolinensis and Anolis sagrei lizards. Ethology 2012, 118, 494-502. [CrossRef]

44. Stuart, Y.E.; Campbell, T.S.; Hohenlohe, P.A.; Reynolds, R.G.; Revell, L.J.; Losos, J.B. Rapid evolution of a native species following invasion by a congener. Science 2014, 346, 463-466. [CrossRef]

45. Christensen, H.A.; De Vasquez, A.M.; Boreham, M.M. Host-feeding patterns of mosquitoes (Diptera: Culicidae) from central Panama. Am. J. Trop. Med. Hyg. 1996, 55, 202-208. [CrossRef]

46. Savage, H.M.; Aggarwal, D.; Apperson, C.S.; Katholi, C.R.; Gordon, E.; Hassan, H.K.; Anderson, M.; Charnetzky, D.; McMillen, L.; Unnasch, E.A.; et al. Host choice and West Nile virus infection rates in blood-fed mosquitoes, including members of the Culex pipiens Complex, from Memphis and Shelby County, Tennessee, 2002-2003. Vector Borne Zoonotic Dis. 2007, 7, 365-386. [CrossRef]

47. Burkett-Cadena, N.D.; Graham, S.P.; Hassan, H.K.; Guyer, C.; Eubanks, M.D.; Katholi, C.R.; Unnasch, T.R. Blood feeding patterns of potential arbovirus vectors of the genus Culex targeting ectothermic hosts. Am. J. Trop. Med. Hyg. 2008, 79, 809-815. [CrossRef]

48. Tempelis, C.H.; Galindo, P. Host-feeding patterns of Culex (Melanoconion) and Culex (Aedinus) mosquitoes collected in Panama. J. Med. Entomol. 1975, 12, 205-209. [CrossRef]

49. Cupp, E.W.; Zhang, D.; Yue, X.; Cupp, M.S.; Guyer, C.; Sprenger, T.R.; Unnasch, T.R. Identification of reptilian and amphibian blood meals from mosquitoes in an eastern equine encephalomyelitis virus focus in central Alabama. Am. J. Trop. Med. Hyg. 2004, 71, 272-276. [CrossRef] 
50. Perkins, S.L.; Rothschild, A.; Waltari, E. Infections of the malaria parasite, Plasmodium floridense, in the invasive lizard, Anolis Sagrei, in Florida. J. Herpetol. 2007, 41, 750-754. [CrossRef]

51. Doan, T.M.; Devlin, B.G.; Greene, K.C. Malaria infection is lower in invasive anoles than native anoles in Central Florida, USA. J. Herpetol. 2019, 53, 22-26. [CrossRef]

52. Klein, T.A.; Akin, D.C.; Young, D.G.; Telford, S.R., Jr. Sporogeny, development and ultrastructure of Plasmodium floridense in Culex erraticus. Int. J. Parasitol. 1988, 18, 711-719. [CrossRef]

53. Cohen, S.B.; Lewoczko, K.; Huddleston, D.B.; Moody, E.; Mukherjee, S.; Dunn, J.R.; Jones, T.F.; Wilson, R.; Moncayo, A.C. Host feeding patterns of potential vectors of eastern equine encephalitis virus at an epizootic focus in Tennessee. Am. J. Trop. Med. Hyg. 2009, 81, 452-456. [CrossRef]

(C) 2019 by the authors. Licensee MDPI, Basel, Switzerland. This article is an open access article distributed under the terms and conditions of the Creative Commons Attribution (CC BY) license (http://creativecommons.org/licenses/by/4.0/). 